\title{
Impact of Direction of Transport on the Evaluation of Inhibition Potencies of Multidrug and Toxin Extrusion Protein 1 Inhibitors ${ }^{\mathbb{\Phi}}$
}

\author{
Asami Saito, Naoki Ishiguro, Masahito Takatani, Bojan Bister, and Hiroyuki Kusuhara \\ Pharmacokinetics and Non-Clinical Safety Department, Nippon Boehringer Ingelheim Co., Ltd., Kobe, Japan (A.S., N.I, M.T., B.B.) \\ and Laboratory of Molecular Pharmaceutics, Graduate School of Pharmaceutical Sciences, The University of Tokyo, Tokyo, \\ Japan (H.K.)
}

Received June 8, 2020; accepted November 23, 2020

\begin{abstract}
Multidrug and toxin extrusion (MATE) transporters are expressed on the luminal membrane of renal proximal tubule cells and extrude their substrates into the luminal side of the tubules. Inhibition of MATE1 can reduce renal secretory clearance of its substrate drugs and lead to drug-drug interactions (DDIs). To address whether IC $\mathbf{C}_{50}$ values of MATE1 inhibitors with regard to their extracellular concentrations are affected by the direction of MATE1-mediated transport, we established an efflux assay of 1-methyl-4-phenylpyridinium $\left(\mathrm{MPP}^{+}\right)$and metformin using the human embryonic kidney 293 model transiently expressing human MATE1. The efflux rate was defined by reduction of the cellular amount of $\mathrm{MPP}^{+}$and metformin for 0.25 minutes shortly after the removal of extracellular $\mathrm{MPP}^{+}$and metformin. Inhibition potencies of 12 inhibitors toward MATE1mediated transport were determined in both uptake and efflux assays. When MPP ${ }^{+}$was used as a substrate, 8 out of 12 inhibitors showed comparable $I_{50}$ values between assays $\left(<4-\right.$ fold). $I_{50}$ values from the efflux assays were higher for cimetidine (9.9-fold),
\end{abstract}

trimethoprim (10-fold), famotidine (6.4-fold), and cephalexin ( $>3.8$ fold). When metformin was used as a substrate, $I_{50}$ values of the tested inhibitors when evaluated using uptake and efflux assays were within 4-fold of each other, with the exception of cephalexin (>4.7-fold). IC $_{50}$ values obtained from the uptake assay using metformin showed smaller $I_{50}$ values than those from the efflux assay. Therefore, the uptake assay is recommended to determine ${ } \mathrm{C}_{50}$ values for the DDI predictions.

\section{SIGNIFICANCE STATEMENT}

In this study, a new method to evaluate $I_{C_{50}}$ values of extracellular added inhibitors utilizing an efflux assay was established. IC $_{50}$ values were not largely different between uptake and efflux directions but were smaller for uptake. This study supports the rationale for a commonly accepted uptake assay with metformin as an in vitro probe substrate for multidrug and toxin extrusion 1-mediated drugdrug interaction risk assessment in drug development.

\section{Introduction}

The multidrug and toxic compound extrusion (MATE) family of transporters is ubiquitously expressed in organisms from several kingdoms of life, including archaea, bacteria, and plants, and exports cationic compounds using the $\mathrm{H}^{+}$or $\mathrm{Na}^{+}$gradient across plasma membranes. The human MATE orthologs MATE1 (SLC47A1) and MATE2-K (SLC47A2) are expressed on the brush-border membrane of proximal tubule cells and work as organic cations $/ \mathrm{H}^{+}$antiporters driven by an $\mathrm{H}^{+}$ gradient (Yonezawa and Inui, 2011a; Motohashi and Inui, 2013). Although 1-methyl-4-phenylpyridinium $\left(\mathrm{MPP}^{+}\right)$and metformin are prototypical substrates of MATEs, extensive studies have identified various compounds as MATE1 and MATE2-K substrates, including endogenous metabolites such as creatinine (Terada and Inui, 2008). Quantitative targeted proteomics revealed abundant MATE1 expression in the human kidney cortex, whereas MATE2-K expression was detectable but below the lower limit of quantification (Prasad et al., 2016), suggesting that MATE1 is the major MATE isoform in the kidney. MATEs also play an important role in several clinical drug-drug

This study was supported by Nippon Boehringer Ingelheim Co., Ltd. https://doi.org/10.1124/dmd.120.000136.

S This article has supplemental material available at dmd.aspetjournals.org. interactions (DDIs) (Tsuda et al., 2009; Kusuhara et al., 2011; Ito et al., 2012), renal toxicities (Yonezawa and Inui, 2011b; Li et al., 2013), and drug efficacy (Becker et al., 2009; Stocker et al., 2013). MATEmediated DDIs can result in a reduction in the renal clearance of coadministered drugs, or other compounds, that are MATE substrates (Ivanyuk et al., 2017). A reversible increase in levels of serum creatinine, a frequently used biomarker for kidney function, can occur by inhibiting its MATE-mediated tubular secretion (Chu et al., 2016; Nakada et al., 2019). Because of the emerging importance of MATE transporters in DDIs, regulatory authorities recently revised their guidelines for drug interaction studies to include MATEs. As such, sponsors now routinely evaluate the in vitro DDI potential of investigational compounds toward these transporters (European Medicines Agency, 2012; Ministry of Health, Labor and Welfare, 2018; U.S. Food and Drug Administration, 2020).

To profile compounds that interact with MATE transporters, the uptake of in vitro probe substrates into cells that overexpress a MATE transporter, defined in this paper as an "uptake assay" or "uptake direction," is one of the most commonly used methods. This methodology assumes that MATEs exhibit symmetric transport in both uptake and efflux directions. Considering the physiologic role of MATEs as efflux transporters in the kidney, there are concerns about the impact of the direction of transport on estimation of $\mathrm{IC}_{50}$ values. Several crystal

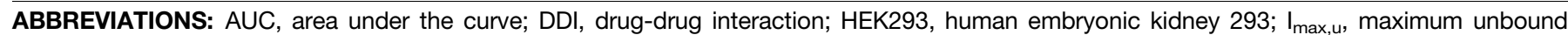
inhibitor concentration; MATE, multidrug and toxin extrusion; $\mathrm{MPP}^{+}$, 1-methyl-4-phenylpyridinium; SLC, solute carrier family. 
structures of MATE orthologs have been reported (NorM-VC from Vibrio cholerae, DinF-BH from Bacillus halodurans, pfMATE from Pyrococcus furiosus, and eMATE from Arabidopsis thaliana) (He et al., 2010; Lu et al., 2013; Tanaka et al., 2013; Miyauchi et al., 2017); however, most of the available structures to date only focus on outwardfacing portions of the protein, and therefore symmetry of MATE transporters across cell membranes is not well understood. Whereas Dangprapai and Wright (2011) revealed that the inward- and outwardfacing MATE1 protein is symmetric by checking the kinetic interaction of $\mathrm{H}^{+}$with MATE1, no information regarding symmetric interaction substances other than $\mathrm{H}^{+}$is available.

In this study, we developed the efflux assay to simply focus on the impact of the direction of transport toward $\mathrm{IC}_{50}$ determination and compared the inhibition potency of 12 known MATE transporter inhibitors with regard to their extracellular concentrations for both uptake and efflux of two MATE1 substrates, $\mathrm{MPP}^{+}$and metformin, in MATE1-overexpressing cells. Furthermore, DDI predictions involving MATE1 were assessed using the $\mathrm{I}_{\max , \mathrm{u}} / \mathrm{IC}_{50}$ approach as currently recommended by regulatory agencies.

\section{Materials and Methods}

Chemicals and Reagents. Unlabeled metformin was purchased from Wako Pure Chemical Industries (Osaka, Japan), and unlabeled $\mathrm{MPP}^{+}$was purchased from Sigma-Aldrich (St. Louis, MO). $\left[{ }^{14} \mathrm{C}\right]$ Metformin $(100 \mathrm{mCi} / \mathrm{mmol})$ and $\left[{ }^{3} \mathrm{H}\right]$ metformin $(8 \mathrm{Ci} / \mathrm{mmol})$ were purchased from Moravek Biochemicals (Brea, $\mathrm{CA}$ ), and $\left[{ }^{3} \mathrm{H}\right] \mathrm{MPP}^{+}(80 \mathrm{Ci} / \mathrm{mmol})$ was purchased from American Radiolabeled Chemicals (Saint Louis, MO). All other chemicals and reagents were of analytical grade and are commercially available.

Cell Culture and Transfection. HEK293 cells transiently expressing human MATE1 were cultured in poly(D-lysine)-coated 24-well plates as described in our previous study (Lechner et al., 2016). Culture medium supplemented with $5 \mathrm{mM}$ sodium butyrate was added approximately 24 hours after transfection to induce transporter gene expression. Uptake and efflux experiments were conducted approximately 48 hours after transfection.

Uptake Experiments Using Transiently Transfected HEK293 Cells. Cells were washed twice and incubated with transport buffer supplemented with $20 \mathrm{mM}$ $\mathrm{NH}_{4} \mathrm{Cl}$ for 10 minutes at $37^{\circ} \mathrm{C}$. The medium was replaced with $\mathrm{NH}_{4} \mathrm{Cl}$-free transport buffer, and cells were incubated for an additional 5 minutes for intracellular preacidification. The composition of transport buffer was as follows: $130 \mathrm{mM} \mathrm{KCl}, 2 \mathrm{mM} \mathrm{KH}_{2} \mathrm{PO}_{4}, 1.2 \mathrm{mM} \mathrm{MgSO}_{4}, 1 \mathrm{mM} \mathrm{CaCl} 2,20 \mathrm{mM}$ HEPES, and $5 \mathrm{mM}$ glucose. Uptake was initiated by replacing buffer with transport buffer containing radiolabeled $\left[{ }^{3} \mathrm{H}\right] \mathrm{MPP}^{+}$or $\left[{ }^{14} \mathrm{C}\right]$ metformin with or without inhibitors. Uptake was terminated at the designated incubation times by removal of drug solution followed by an addition of ice-cold transport buffer. The cells were then washed three times with $0.5 \mathrm{ml}$ of ice-cold transport buffer. Cells were solubilized with $\mathrm{NaOH}$ for 1 hour at $37^{\circ} \mathrm{C}$, and the lysate was neutralized by adding $\mathrm{HCl}$. Aliquots of the cell lysates were transferred to scintillation vials containing scintillation cocktail (Ultima Gold XR; PerkinElmer, Waltham, MA), and radioactivity was measured in a liquid scintillation counter (TRI-CARB 3110TR; PerkinElmer). The protein concentration was determined using the Lowry method with bovine serum albumin as the protein standard (Lowry et al., 1951).

Efflux Experiments Using Transiently Transfected HEK293 Cells. Cells were washed twice and incubated with $\mathrm{NH}_{4} \mathrm{Cl}$-free transport buffer for 30 minutes at $37^{\circ} \mathrm{C}$. Then, medium was replaced with $\mathrm{NH}_{4} \mathrm{Cl}$-free transport buffer containing $\left[{ }^{3} \mathrm{H}\right] \mathrm{MPP}^{+}$or $\left[{ }^{3} \mathrm{H}\right]$ metformin and incubated for an additional 10 minutes to preload the labeled substrate into the cells. Efflux was initiated by replacing preloading buffer with transport buffer supplemented with $20 \mathrm{mM} \mathrm{NH}_{4} \mathrm{Cl}$ with and without inhibitors. Termination of efflux, cell lysis, radioactivity measurement, and determination of protein concentration were done as described in uptake experiments (Supplemental Fig. 3). Total intracellular substrate concentration was determined assuming $6.5 \mu 1$ as cellular volume per milligram protein (Gillen and Forbush, 1999).

Determination of Intracellular $\mathbf{p H}$. Intracellular $\mathrm{pH}$ was determined using a pH-sensitive fluorescent dye. HEK293 cells expressing MATE1 were preloaded with $2^{\prime}, 7^{\prime}$-bis-(2-carboxyethyl)-5-(and-6)-carboxyfluorescein acetoxymethyl at $37^{\circ} \mathrm{C}$ for 30 minutes. The fluorescence intensity (excitation at 488 and $460 \mathrm{~nm}$, emission at $535 \mathrm{~nm}$ ) was measured, and the ratio of fluorescence from the two wavelengths was monitored in a fluorescence plate reader (Enspire; PerkinElmer). Intracellular pH of MATE1-HEK293 cells was calibrated using standardized $\mathrm{pH}$ buffers containing $10 \mu \mathrm{M}$ nigericin (Thomas et al., 1979).

Data Analysis. MATE1-mediated uptake clearance was calculated by normalizing the amount of radioactivity inside the cells to that in the buffer and the protein concentration in each well using the following equation:

$$
\text { Uptake } C L=\frac{X_{\text {cell }}}{C_{\text {buffer }}},
$$

where Uptake $C L$ is the uptake clearance (microliters per designated time point per milligram), $X_{\text {cell }}$ is the radioactivity in the cells (dpm per designated time per well), and $C_{\text {buffer }}$ is the concentration of radioactivity in the buffer (dpm per microliter). Uptake CL was normalized by the amount of total cellular protein (milligrams per well). MATE1-mediated uptake was calculated by subtracting the uptake into mock vector-transfected cells from that into MATE1-transfected cells.

MATE1-mediated efflux clearance was calculated by subtracting the remaining amount of substrate within the cells from that in the presence of $100 \mu \mathrm{M}$ pyrimethamine, which was assumed to inhibit MATE1 completely, and was normalized by area under the curve (AUC) of intracellular substrate concentration-time curve and protein concentration in each well using the following equation:

$$
\text { Efflux } C L=\frac{X_{t_{n}, p y r}-X_{t_{n}}}{A U C_{0-t_{n}}},
$$

where Efflux $C L$ is the efflux clearance (microliters per designated time per milligram), $X_{t_{n}, p y r}$ is the radioactivity remaining in the cells at $t_{n}$ in the presence of $100 \mu \mathrm{M}$ pyrimethamine (dpm per designated time per well), $X_{t_{n}}$ is the radioactivity remained in the cells at $t_{n}$ (dpm per designated time per well), and Efflux $C L$ was normalized by the amount of protein (milligrams per well).

Because the uptake of probe substrates during the preloading phase is largely different, and it is difficult to use the identical initial intracellular concentration between MATE1-transfected cells and mock vector-transfected cells, MATE1transfected cells incubated in presence of $100 \mu \mathrm{M}$ pyrimethamine were used as control cells assuming no MATE1 activity.

Decrease of the total intracellular substrate concentration during efflux incubations was assumed to follow first-order elimination, and the change of intracellular concentration over time was described by

$$
A U C_{0-t_{n}}=\frac{t_{n} \times\left(C_{0}-C_{t_{n}}\right)}{\ln \left(C_{0} / C_{t_{n}}\right)},
$$

where $A U C$ is area under the total intracellular substrate concentration-time curve (micromolar $\times$ minute), $t_{\mathrm{n}}$ is efflux incubation time (minutes), $C_{0}$ is the initial total intracellular substrate concentration (micromolar), and $C_{t_{n}}$ (micromolar) is the total intracellular substrate concentration at $t_{\mathrm{n}} \cdot t_{\mathrm{n}}$ was set to 0.25 minutes as the minimum feasible time.

The $\mathrm{IC}_{50}$ of each inhibitor was determined using GraphPad PRISM software version 8.3.0 (GraphPad Software, San Diego, CA) based on the four-parameter logistic equation

$$
C L=C L_{\min }+\left(\frac{\left(C L_{\max }-C L_{\min }\right)}{\left.1+10^{\left(\left(\log I C_{50}-I\right) \times H i l l\right)}\right)},\right.
$$

where $C L$ represents the uptake or efflux clearance, $I$ is the concentration of inhibitor in the extracellular buffers, and Hill is the slope factor.

\section{Results}

Effect of $\mathrm{NH}_{4} \mathrm{Cl}$ on Intracellular $\mathrm{pH}$ to Modulate the $\mathrm{H}^{+}$ Gradient. Acute exposure to $\mathrm{NH}_{4} \mathrm{Cl}$ increased intracellular $\mathrm{pH}$ apparently to around $\mathrm{pH} 8.0$ at all $\mathrm{NH}_{4} \mathrm{Cl}$ concentrations (a pH greater than 8 could not be reliably determined because of a limitation of the method, Supplemental Fig. 1). At $20 \mathrm{mM} \mathrm{NH}_{4} \mathrm{Cl}$, the intracellular $\mathrm{pH}$ was greater than 8.0 immediately after the medium change. It was 
A

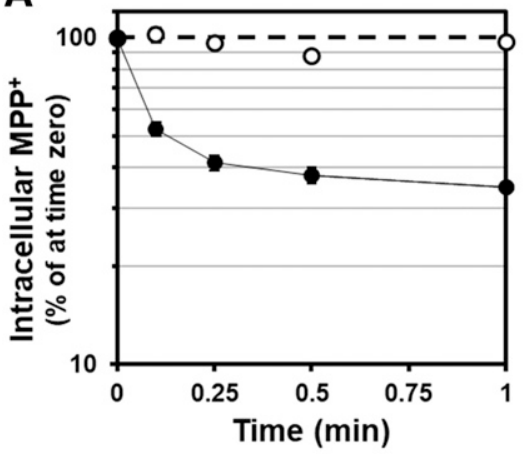

B

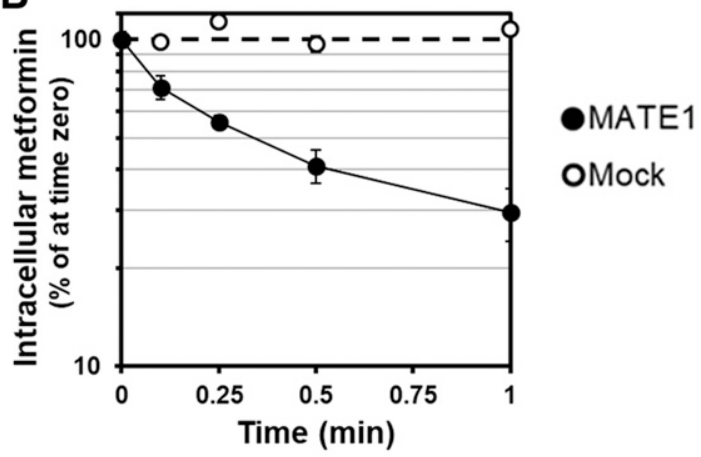

Fig. 1. Time profiles of intracellular $\left[{ }^{3} \mathrm{H}\right] \mathrm{MPP}^{+}$ (A) and $\left[{ }^{3} \mathrm{H}\right]$ metformin (B) in MATE1expressing HEK293 cells. After preloading $\left[{ }^{3} \mathrm{H}\right] \mathrm{MPP}^{+}(0.01 \mu \mathrm{M})$ and $\left[{ }^{3} \mathrm{H}\right]$ metformin $(0.1$ $\mu \mathrm{M})$ for 10 minutes, efflux was initiated in

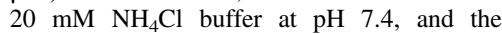
remaining concentrations of substrates in the cells were measured. Each point represents the mean value \pm S.D. $(n=3)$. maintained up to 10 minutes after the medium change and then gradually returned to basal $\mathrm{pH}$ (Supplemental Fig. 2).

Washout of $\mathrm{NH}_{4} \mathrm{Cl}$ by replacement with buffer lacking $\mathrm{NH}_{4} \mathrm{Cl}$ decreased intracellular $\mathrm{pH}$ in a concentration-dependent manner. In our previous study, in which $20 \mathrm{mM} \mathrm{NH}_{4} \mathrm{Cl}$ was used for intracellular preacidification (Lechner et al., 2016), the intracellular $\mathrm{pH}$ in the uptake assay was around 6.5 and was maintained for several minutes, which is a sufficient duration, as the incubation time was 1 minute. Subsequently, $20 \mathrm{mM} \mathrm{NH}_{4} \mathrm{Cl}$ was used in all experiments to generate an artificial $\mathrm{pH}$ gradient.

Time and Concentration-Dependent Efflux of $\left[{ }^{3} \mathrm{H}\right] \mathrm{MPP}^{+}$and $\left[{ }^{3} \mathbf{H}\right]$ Metformin. $\mathrm{MPP}^{+}$and metformin were selected as probe substrates in this study because they are the most-studied prototypical and/or clinically relevant organic cations for MATE assays. In addition, $\mathrm{IC}_{50}$ values toward MATE1 using these two substrates were comparable in uptake assays in previous studies (Lechner et al., 2016; MartínezGuerrero et al., 2016b).

The efflux of $\mathrm{MPP}^{+}$and metformin from MATE1-expressing cells or mock vector-transfected cells is shown in Fig. 1. A time-dependent decrease of intracellular substrate concentration was only observed in MATE1-expressing cells but not in control cells. The decrease of intracellular substrates was curve-linear in semi-log plots. In particular, this tendency was remarkable when $\mathrm{MPP}^{+}$was used (Fig. 1). According to the preliminary experiment, it was not practical to determine $\mathrm{IC}_{50}$ values in incubation times shorter than 0.25 minutes because of the small change in the cellular amount of $\mathrm{MPP}^{+}$or metformin, resulting in a nonnegligible experimental variability of the efflux rates. The subsequent analysis was conducted at 0.25 minutes as the minimum feasible incubation time in further assays for both probe substrates.

Efflux clearance of $\mathrm{MPP}^{+}$and metformin from MATE1-expressing cells decreased as shown by an increase of intracellular concentration of substrates (Supplemental Fig. 4), resulting in apparent $K_{m}$ values of $10-100 \mu \mathrm{M}\left(\mathrm{MPP}^{+}\right)$and $100-1000 \mu \mathrm{M}$ (metformin), respectively. The nominal concentrations of $\mathrm{MPP}^{+}$and metformin in preloading solutions were set at 0.05 and $0.75 \mu \mathrm{M}$, respectively, because the experimentally determined total intracellular concentrations of the substrates used were 1 and $10 \mu \mathrm{M}$, which is similar to the substrate concentrations used in the inhibition study in the uptake direction (Lechner et al., 2016).

Comparison of Uptake and Efflux $\mathrm{IC}_{50} \mathrm{Using}_{\mathrm{MPP}^{+}}$and Metformin as a Substrate. Inhibition potencies of dolutegravir, vandetanib, cephalexin, ranolazine, lansoprazole, and cobicistat, which are reported to cause clinical DDIs via inhibition of MATE1, were investigated in the uptake direction (Supplemental Fig. 5; Table 1), along with the six compounds investigated previously (Lechner et al., 2016). Additionally, inhibition potencies of these 12 compounds were determined in the efflux direction. In both assays, $\mathrm{IC}_{50}$ values were defined by inhibitor concentrations in the buffer added to the outside of the cells (Figs. 2-4; Supplemental Fig. 5; Table 1).

TABLE 1

DDI risk assessment based on $\mathrm{IC}_{50}$ values from uptake/efflux directions and plasma unbound $C_{\max }$

$\mathrm{IC}_{50}$ values were estimated by nonlinear regression analysis and are given as means \pm S.D.

\begin{tabular}{|c|c|c|c|c|c|c|c|c|}
\hline \multirow{3}{*}{ Inhibitor } & \multicolumn{4}{|c|}{$\mathrm{IC}_{50}$, MATE1 } & \multirow{3}{*}{$C_{\max , \mathrm{u}}$} & \multirow{3}{*}{ Metformin AUC Change } & \multirow{3}{*}{$\begin{array}{c}C_{\max , \mathrm{u}} / \mathrm{IC}_{50, \text { Metfromin }} \\
\text { Uptake }\end{array}$} & \multirow[b]{3}{*}{ Efflux } \\
\hline & \multicolumn{2}{|c|}{$\mathrm{MPP}^{+}$} & \multicolumn{2}{|c|}{ Metformin } & & & & \\
\hline & Uptake & Efflux & Uptake & Efflux & & & & \\
\hline & & & $\mu M$ & & & $\%$ & & \\
\hline Pyrimethamine* & $0.492 \pm 0.039$ & $1.19 \pm 0.061$ & $0.313 \pm 0.052$ & $0.502 \pm 0.058$ & 0.298 & $35.3-170$ & 0.95 & 0.59 \\
\hline Cimetidine* & $4.43 \pm 0.05$ & $43.8 \pm 0.13$ & $2.56 \pm 0.04$ & $6.12 \pm 0.077$ & 7.74 & $46.2-54.2$ & 3.0 & 1.3 \\
\hline Trimethoprim* & $8.16 \pm 0.06$ & $84.5 \pm 0.087$ & $4.13 \pm 0.09$ & $11.3 \pm 0.13$ & 8.88 & $21.5-68.6$ & 2.2 & 0.79 \\
\hline Quinidine* & $6.77 \pm 0.08$ & $15.5 \pm 0.094$ & $5.82 \pm 0.06$ & $5.00 \pm 0.12$ & 1.34 & No data & 0.23 & 0.27 \\
\hline Ondansetron* & $0.797 \pm 0.025$ & $0.935 \pm 0.15$ & $0.436 \pm 0.083$ & $0.624 \pm 0.19$ & 0.0471 & 21 & 0.11 & 0.076 \\
\hline Famotidine* & $1.670 \pm 0.03$ & $10.7 \pm 0.12$ & $0.905 \pm 0.046$ & $3.11 \pm 0.12$ & 1 & 2.7 & 1.1 & 0.32 \\
\hline Dolutegravir & $7.12 \pm 0.085$ & $23.8 \pm 0.23$ & $3.04 \pm 0.086$ & $9.07 \pm 0.30$ & 0.180 & $78.9-145$ & 0.059 & 0.020 \\
\hline Vandetanib & $3.36 \pm 0.06$ & $3.52 \pm 0.17$ & $2.39 \pm 0.034$ & $1.60 \pm 0.13$ & 0.102 & 73.3 & 0.043 & 0.064 \\
\hline Cephalexin & $2614 \pm 0.02$ & $>10,000$ & $2110 \pm 0.043$ & $>10,000$ & 69.3 & 23.9 & 0.033 & N.A. \\
\hline Ranolazine & $88.1 \pm 0.043$ & $111 \pm 0.092$ & $48.7 \pm 0.061$ & $66.3 \pm 0.31$ & 1.85 & $38.5-83$ & 0.038 & 0.028 \\
\hline Lansoprazole & $60.1 \pm 0.049$ & $148 \pm 0.22$ & $44.0 \pm 0.056$ & $66.5 \pm 0.24$ & 0.0883 & 11.8 & 0.0020 & 0.0013 \\
\hline Cobicistat & $5.29 \pm 0.087$ & $12.2 \pm 0.11$ & $2.75 \pm 0.083$ & $5.27 \pm 0.23$ & 0.054 & No data & 0.020 & 0.010 \\
\hline
\end{tabular}

$C_{\max , u}$, plasma unbound $C_{\max } ;$ N.A., not applicable.

${ }^{*} \mathrm{IC}_{50}$ values obtained by uptake assay were from Lechner et al. (2016). 
A

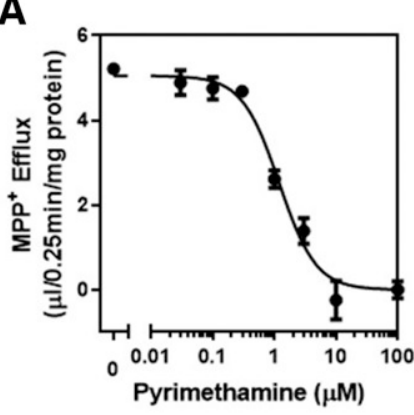

E

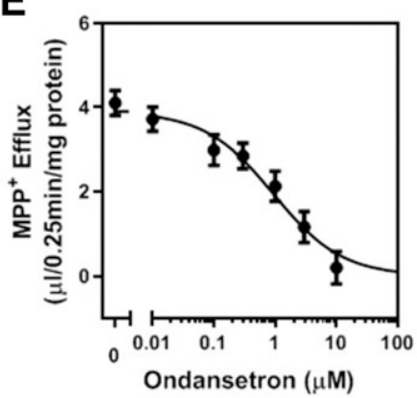

I

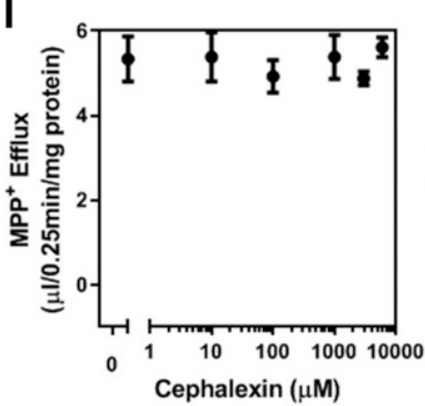

B

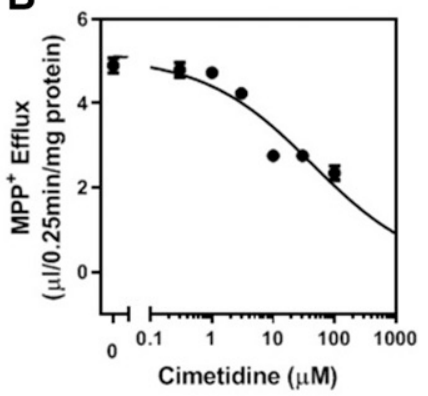

$\mathbf{F}$
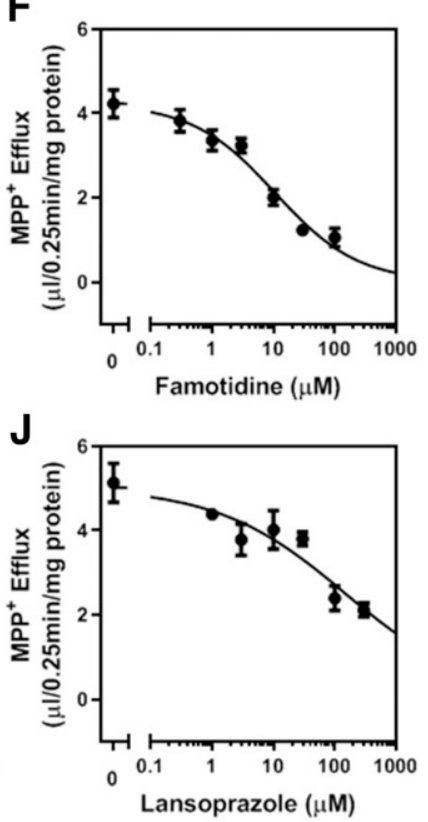

C

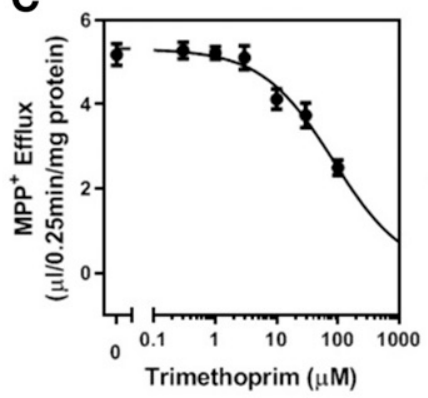

G

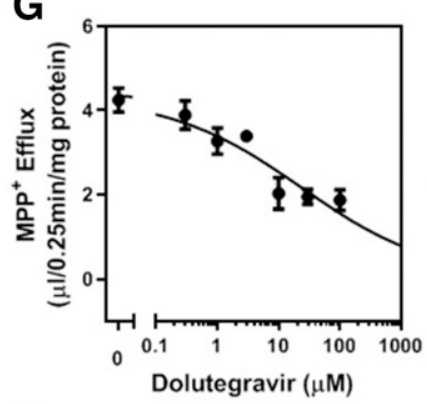

$\mathbf{K}$

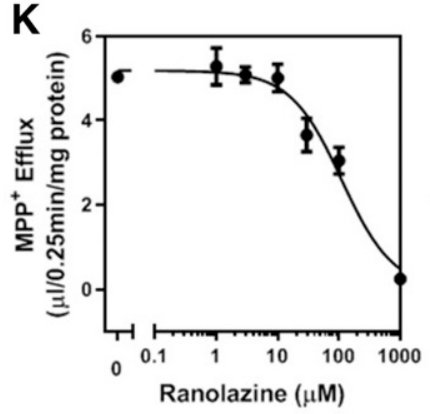

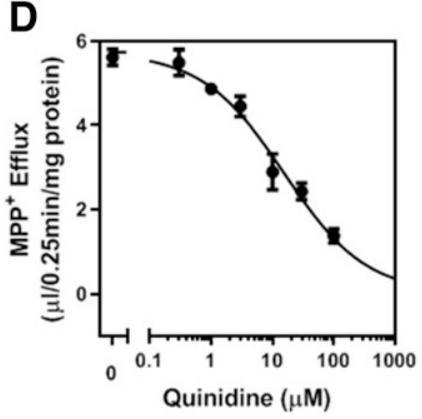

H

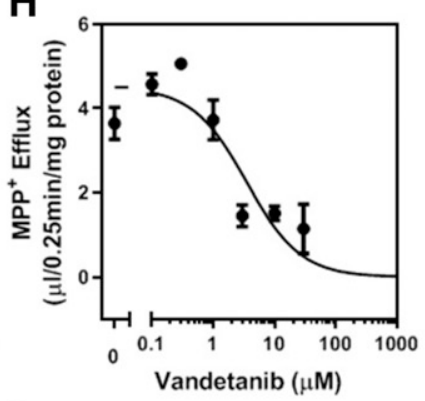

L

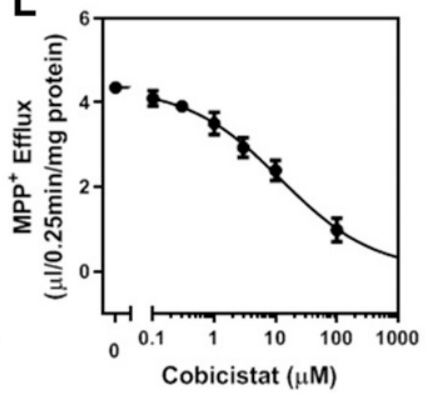

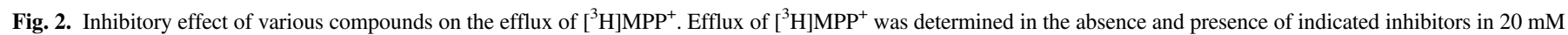

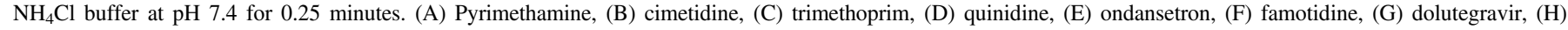
vandetanib, (I) cephalexin, $(\mathrm{J})$ lansoprazole, $(\mathrm{K})$ ranolazine and $(\mathrm{L})$ cobicistat. Each point represents the mean value \pm S.E. $(n=3)$.

When $\mathrm{MPP}^{+}$was used as a substrate, differences in $\mathrm{IC}_{50}$ values between uptake and efflux mode were within 4-fold for 8 out of the 12 inhibitors. For cimetidine, trimethoprim, famotidine, and cephalexin, $\mathrm{IC}_{50}$ values were greater in efflux mode, showing 9.9-fold, 10-fold, 6.4fold, and $>3.8$-fold differences when compared with the uptake mode, respectively (Fig. 4; Table 1). When metformin was used as a substrate, all $\mathrm{IC}_{50}$ values, except for cephalexin, were within 4-fold between uptake and efflux directions (Fig. 4; Table 1).

\section{Discussion}

The most commonly used in vitro inhibition assay against MATE1 determines the inhibition potency of extracellularly added compounds by assessing the uptake of probe substrates into MATE1-expressing cells. Thus, this commonly used assay assumes $\mathrm{IC}_{50}$ values are identical and independent from whichever direction the substrates are transported. To address whether DDI risk predictions based on regulatory guidelines are different or not depending on the direction of transport, $\mathrm{IC}_{50}$ values of various MATE1 inhibitors were generated in "uptake mode" and "efflux mode" based on their extracellular concentrations.

To achieve this, we developed an efflux inhibition assay for MATE1 after preloading two different substrates, $\mathrm{MPP}^{+}$and metformin, into MATE1-overexpressing cells. Initially, we aimed to measure the amount of substrate being effluxed into the medium. However, because of carryover from the preloading solution and loss of substrate from the cells during necessary subsequent washing steps, efflux clearance was determined based on the time-concentration profiles of remaining substrate within the cells (Fig. 1). The time-dependent decrease in the cells suggested at least two rate constants, one fast and the other much slower, in both substrates, and this phenomenon was more obvious, especially for $\mathrm{MPP}^{+}$. Organic cations are distributed into acidic subcellular compartments such as endosomes (Martínez-Guerrero et al., 2016a), which is referred to as endosomal trapping. According to Martínez-Guerrero, substrate release from endosomes was slow, and the rate constant for initial efflux of $\mathrm{MPP}^{+}$from MATE1-CHO cells was not changed regardless of the disruption of endosomal trapping by the addition of V-type $\mathrm{H}^{+}$-ATPase inhibitor. Therefore, assuming that the fast phase represents the efflux from the shallow compartment of the cells, we set 0.25 minutes as a minimum feasible incubation time for further efflux assay. As a preliminary experiment, we examined the dependence of the efflux clearance on the preloaded substrate concentrations (Supplemental Fig. 4). The efflux clearance was decreased, along with an increase in the intracellular concentration, presumably because of the saturation of MATE1-mediated efflux. Apparent $\mathrm{K}_{\mathrm{m}}$ values for $\mathrm{MPP}^{+}$and metformin were estimated in the rage of 10-100 and 100-1000 $\mu \mathrm{M}$, respectively, which were not largely different from reported $\mathrm{K}_{\mathrm{m}}$ values of MATE1-mediated $\mathrm{MPP}^{+}$and metformin in the uptake direction (47.6 and $208 \mu \mathrm{M}$, respectively) (Lechner et al., 2016). 
A

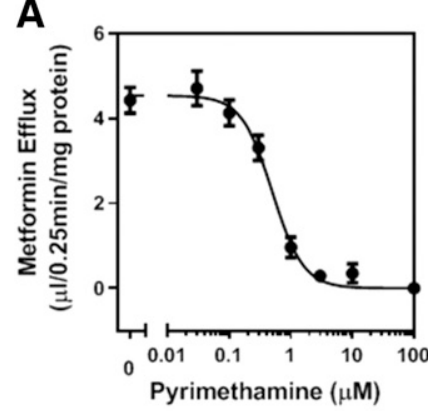

E

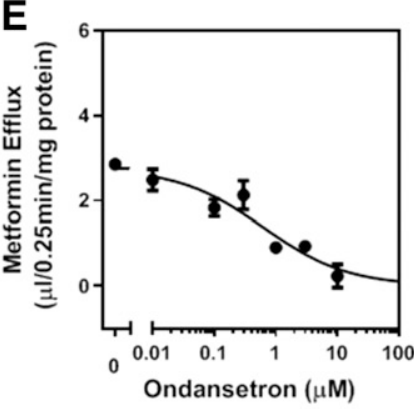

I

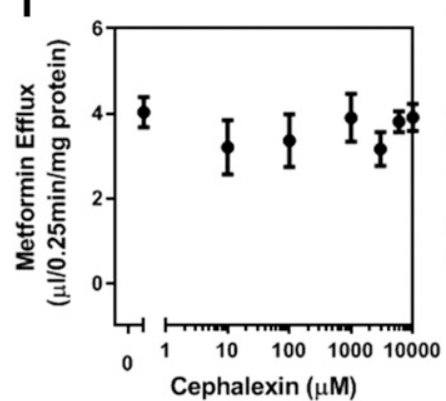

B

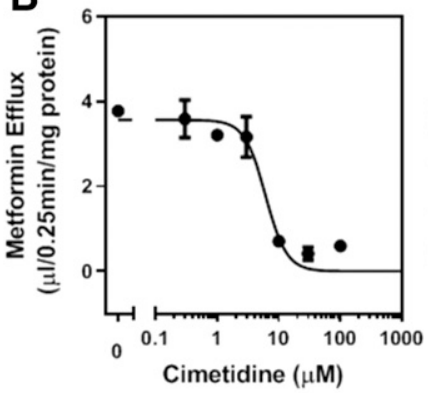

$F$

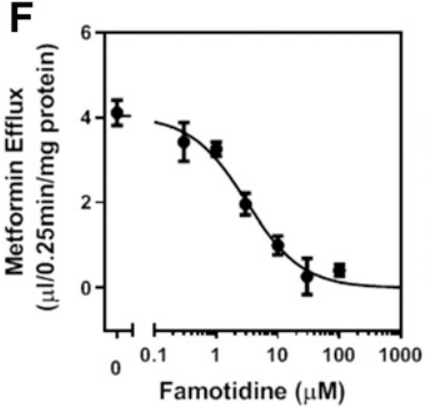

J

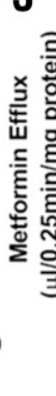

C

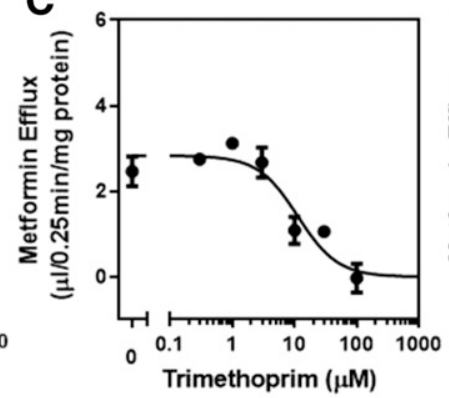

G

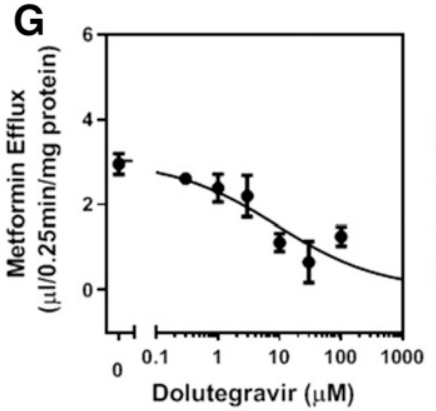

K

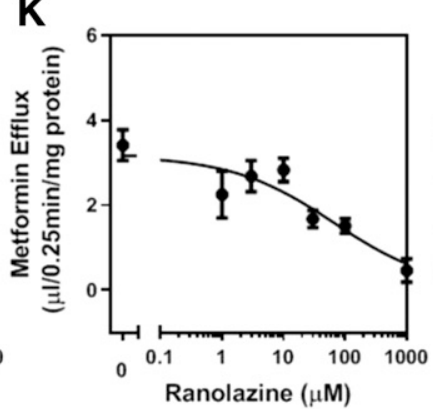

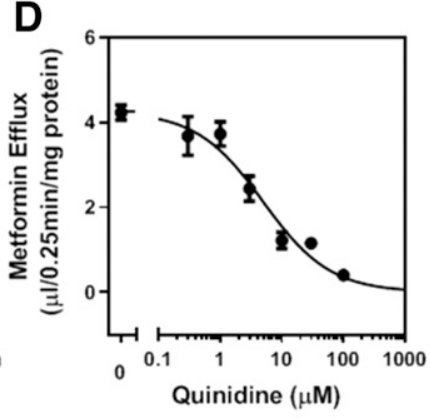

$\mathrm{H}$

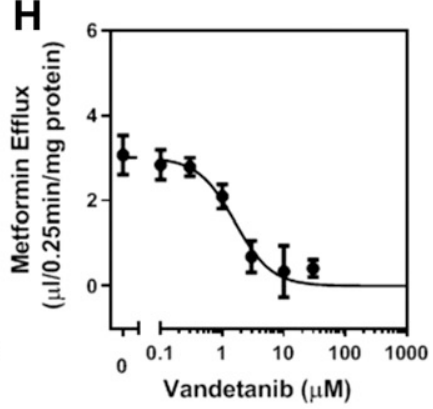

L

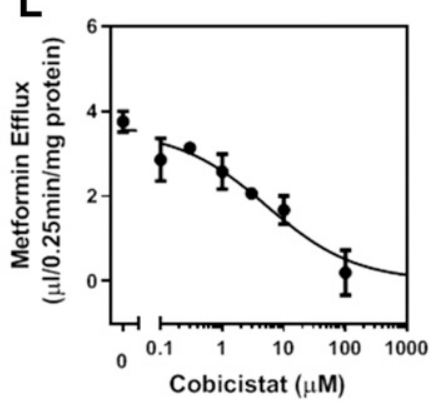

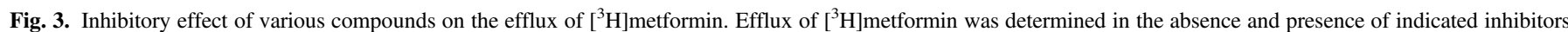

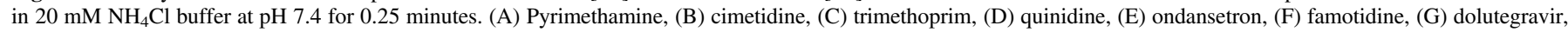
(H) vandetanib, $(\mathrm{I})$ cephalexin, $(\mathrm{J})$ lansoprazole, $(\mathrm{K})$ ranolazine and $(\mathrm{L})$ cobicistat. Each point represents the mean value \pm S.E. $(n=3)$.

Approximation accuracy of these apparent $K_{m}$ values for the true $K_{m}$ depends on the intracellular unbound fraction.

This study examined the direction and substrate dependence of $\mathrm{IC}_{50}$ values for the MATE1 substrates $\mathrm{MPP}^{+}$and metformin by comparing $\mathrm{IC}_{50}$ values obtained in uptake and efflux mode (Fig. 4A) and by comparing $\mathrm{IC}_{50}$ values between $\mathrm{MPP}^{+}$and metformin (Fig. 4B). Regarding direction-dependent inhibition, differences in $\mathrm{IC}_{50}$ values for 8 out of 12 compounds were within 4-fold when comparing uptake and efflux mode when $\mathrm{MPP}^{+}$was used as the probe substrate, although $\mathrm{IC}_{50}$ values for cimetidine, trimethoprim, famotidine, and cephalexin
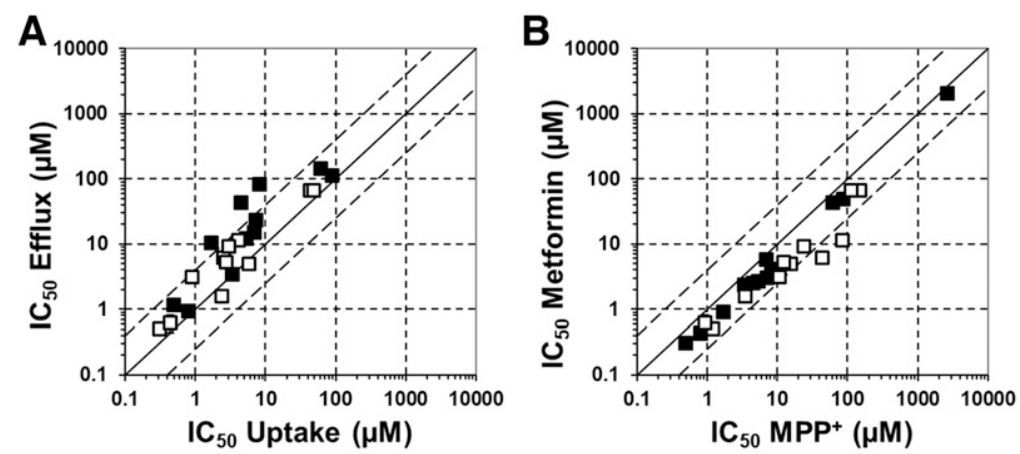

Fig. 4. Comparison of $\mathrm{IC}_{50}$ values from the uptake and efflux direction using $\mathrm{MPP}^{+}$and metformin as probe substrates. $\mathrm{IC}_{50}$ values were determined by nonlinear regression analysis and compared between different transport directions [uptake and efflux (A)] and different substrates $\left[\mathrm{MPP}^{+}\right.$and metformin (B)]. $\mathrm{IC}_{50}$ values of cephalexin in the efflux direction were not plotted because there was no observed inhibition at the highest concentration $(10 \mathrm{mM})$. The black line represents the line of unity, and the dotted lines represent 4-fold errors. 
differed by greater than 4-fold (Fig. 4A). When metformin was used as the probe substrate, the difference in $\mathrm{IC}_{50}$ values between uptake and efflux mode were within 4-fold for every inhibitor tested except cephalexin, which showed very weak inhibition in both assays (Fig. 4A). Regarding substrate dependence, all 12 compounds showed almost identical $\mathrm{IC}_{50}$ values $(<2.3$-fold) for both substrates in uptake assays. Our results are therefore consistent with previously reported substrate-independent $\mathrm{IC}_{50}$ values for $\mathrm{MPP}^{+}$and metformin (Lechner et al., 2016; Martínez-Guerrero et al., 2016a). On the other hand, $\mathrm{IC}_{50}$ values for $\mathrm{MPP}^{+}$showed a tendency to be greater than those for metformin in efflux assays. Still, 10 out of the 12 compounds showed differences within 4-fold (Fig. 4B). The mechanism underlying the different substrate dependencies in either the uptake or efflux direction is not yet fully understood. Although this study carefully designed the efflux assays, this study cannot exclude the possibility that inhibitors interact with MATE1 from inside of the cells or by inhibiting the intracellular binding or lysosomal trapping. Since the efflux clearance was calculated using the total concentrations, this parameter theoretically comprises the intrinsic efflux clearance and intracellular unbound fraction. Even during the short incubation time of 0.25 minutes, the inhibitors can distribute to the cells depending on their passive permeability, participate in MATE1 inhibition, and modify the intracellular binding and lysosomal trapping. And this fact therefore indicates difficulties in both efflux and uptake inhibition studies to discriminate MATE1 inhibition from the extracellular space from that from the intracellular space completely as far as the nonpolarized cells are used as host cells. Yet from the viewpoint of preferring a conservative approach to assess DDI to mitigate any risk for patients, we believe that the uptake assay using metformin as the in vitro probe substrate offers the best condition to determine $\mathrm{IC}_{50}$ values of investigational drugs as inhibitors of MATE1.

We checked the impact of $\mathrm{IC}_{50}$ differences between uptake and efflux direction on predictions of MATE1-mediated clinical DDI risk using $\mathrm{IC}_{50}$ values based on metformin as a substrate. The DDI risk assessment according to the most conservative cutoff criteria $\left(\mathrm{I}_{\max , \mathrm{u}} / \mathrm{IC}_{50}>0.02\right)$ from the latest DDI guidelines from health authorities (Ministry of Health, Labor and Welfare, 2018) provided comparable results between uptake and efflux assays for all compounds. The assessment returned correct predictions of the AUC increase for 9 of the 10 drugs using the $\mathrm{I}_{\mathrm{max}, \mathrm{u}} / \mathrm{IC}_{50}$ approach (Table 1), with the only exception being famotidine. The calculated $\mathrm{I}_{\max , \mathrm{u}} / \mathrm{IC}_{50}$ values were 1.10 in the uptake direction and 0.322 in the efflux direction for famotidine, which are higher than the regulatory cutoff of 0.02 ; nevertheless, famotidine instead increased renal clearance of metformin, which was considered a result of modification of other sites by famotidine, such as urine $\mathrm{pH}$ modification and inhibition of reabsorption (Hibma et al., 2016). The unbound concentrations of MATE1 inhibitors in the plasma empirically seem to work as surrogates of those inside and/or lumen of the proximal tubules from where the inhibitors can address to MATE1. For instance, the quantitative analysis of dose-dependent effect of pyrimethamine on the renal clearance of metformin yielded apparent $\mathrm{IC}_{50}$ values defined from its plasma concentrations comparable with the corresponding in vitro $\mathrm{IC}_{50}$ values (Miyake et al., 2020). It remains a challenge to estimate the clinically relevant unbound concentrations of MATE1 inhibitors in the kidney for more precise prediction, particularly when the transporters could concentrate or actively remove inhibitors inside the cells.

Efflux clearances of $\mathrm{MPP}^{+}$and metformin were 4- to 6.5-fold smaller compared with uptake clearances $\left(\mathrm{MPP}^{+}: 20\right.$ vs. 130 , metformin: 14 vs. $55 \mu \mathrm{l} / \mathrm{min}$ per milligram), although the same $\mathrm{NH}_{4} \mathrm{Cl}$ concentration (20 $\mathrm{mM}$ ) was used. Since efflux clearance was based on the total intracellular concentration, different unbound intracellular concentrations might account for the discrepancy. We further speculate that a difference in the delta proton concentration between the outside and the inside of the cells might be one underlying mechanism. Considering that acute exposure to $20 \mathrm{mM} \mathrm{NH}_{4} \mathrm{Cl}$ increased intracellular $\mathrm{pH}$ to 8.0 when the initial intracellular $\mathrm{pH}$ was 7.0 in another experiment (data not shown), the intracellular $\mathrm{pH}$ in the efflux assay in which the initial intracellular $\mathrm{pH}$ was 7.4 was estimated to be about 8.4 , although a $\mathrm{pH}$ greater than 8.0 could not be measured because of a limitation of the method. In theory, the proton concentration in the efflux direction is 40 $\mathrm{nM}$ in the buffer ( $\mathrm{pH} 7.4$ ) and $4-10 \mathrm{nM}$ within the cells (assuming the intracellular $\mathrm{pH}$ is 8.0-8.4), whereas the proton concentration in the uptake direction is $400 \mathrm{nM}$ (pH 6.4) inside the cells and $40 \mathrm{nM}$ in buffer (pH 7.4). Although the relative difference between extracellular and intracellular $\mathrm{pH}$ value is about one in both assay conditions, the absolute values of $\mathrm{H}^{+}$concentrations, however, differ almost 10 -fold. This might affect the duration of initial velocities for uptake and efflux and may have caused an underestimation of efflux clearance under the current conditions.

We compared $\mathrm{IC}_{50}$ values of 12 MATE1 inhibitors in both uptake and efflux directions. The $\mathrm{IC}_{50}$ values obtained from the uptake assay had a propensity to generate different $\mathrm{IC}_{50}$ values from those obtained from the efflux assay as long as metformin was used as the in vitro probe substrate. Moreover, the predictions of clinical inhibition of MATE1 using the $\mathrm{I}_{\text {max, }} / \mathrm{IC}_{50}$ approach according to the most current regulatory guidance provided accurate predictions of AUC increases for 9 of the 10 inhibitors. The new assay tools, which can evaluate the MATE1 inhibitions separately from outside and from inside the cells, may be expected to produce more physiologically relevant $\mathrm{IC}_{50}$ values. From the viewpoint of drug development in pharmaceutical industries, together with our previous study (Lechner et al., 2016), we recommend the uptake assay using metformin as an in vitro probe substrate to determine $\mathrm{IC}_{50}$ values of new chemical entities for DDI risk assessment.

\section{Acknowledgments}

The excellent technical assistance of Saki Ichimura and Michiru Miyake in performing the in vitro experiments at Nippon Boehringer Ingelheim is gratefully acknowledged. We also thank Dr. Caroline Maclean at Nippon Boehringer Ingelheim and Drs. Mitchell E. Taub and Stephanie Piekos at Boehringer Ingelheim Pharmaceuticals for editing a draft of this manuscript.

\section{Authorship Contributions}

Participated in research design: Saito, Ishiguro, Takatani, Bister, Kusuhara. Conducted experiments: Saito, Takatani.

Performed data analysis: Saito, Takatani, Kusuhara.

Wrote or contributed to the writing of the manuscript: Saito, Ishiguro, Kusuhara.

\section{References}

Becker ML, Visser LE, van Schaik RH, Hofman A, Uitterlinden AG, and Stricker BH (2009) Genetic variation in the multidrug and toxin extrusion 1 transporter protein influences the glucose-lowering effect of metformin in patients with diabetes: a preliminary study. Diabetes $\mathbf{5 8}$ 745-749.

Chu X, Bleasby K, Chan GH, Nunes I, and Evers R (2016) The complexities of interpreting reversible elevated serum creatinine levels in drug development: does a correlation with inhibition of renal transporters exist? Drug Metab Dispos 44:1498-1509.

Dangprapai Y and Wright SH (2011) Interaction of $\mathrm{H}^{+}$with the extracellular and intracellular aspects of hMATE1. Am J Physiol Renal Physiol 301:F520-F528.

European Medicines Agency (2012) EMA guideline on the investigation of drug interactions. 2012. Final CPMP/EWP/560/95.

Gillen CM and Forbush B III (1999) Functional interaction of the K-Cl cotransporter (KCC1) with the Na-K-Cl cotransporter in HEK-293 cells. Am J Physiol 276:C328-C336.

He X, Szewczyk P, Karyakin A, Evin M, Hong WX, Zhang Q, and Chang G (2010) Structure of a cation-bound multidrug and toxic compound extrusion transporter. Nature 467:991-994.

Hibma JE, Zur AA, Castro RA, Wittwer MB, Keizer RJ, Yee SW, Goswami S, Stocker SL, Zhang $\mathrm{X}$, Huang Y, et al. (2016) The effect of famotidine, a MATE1-selective inhibitor, on the pharmacokinetics and pharmacodynamics of metformin. Clin Pharmacokinet 55:711-721. Ito S, Kusuhara H, Yokochi M, Toyoshima J, Inoue K, Yuasa H, and Sugiyama Y (2012) Competitive inhibition of the luminal efflux by multidrug and toxin extrusions, but not basolateral uptake by organic cation transporter 2 , is the likely mechanism underlying the pharmacokinetic drug-drug interactions caused by cimetidine in the kidney. J Pharmacol Exp Ther 340:393-403. 
Ivanyuk A, Livio F, Biollaz J, and Buclin T (2017) Renal drug transporters and drug interactions. Clin Pharmacokinet 56:825-892.

Kusuhara $\mathrm{H}$, Ito $\mathrm{S}$, Kumagai $\mathrm{Y}$, Jiang $\mathrm{M}$, Shiroshita $\mathrm{T}$, Moriyama $\mathrm{Y}$, Inoue $\mathrm{K}$, Yuasa $\mathrm{H}$, and Sugiyama Y (2011) Effects of a MATE protein inhibitor, pyrimethamine, on the renal elimination of metformin at oral microdose and at therapeutic dose in healthy subjects. Clin Pharmacol Ther 89:837-844.

Lechner C, Ishiguro N, Fukuhara A, Shimizu H, Ohtsu N, Takatani M, Nishiyama K, Washio I, Yamamura N, and Kusuhara H (2016) Impact of experimental conditions on the evaluation of interactions between multidrug and toxin extrusion proteins and candidate drugs. Drug Metab Dispos 44:1381-1389.

Li Q, Guo D, Dong Z, Zhang W, Zhang L, Huang SM, Polli JE, and Shu Y (2013) Ondansetron can enhance cisplatin-induced nephrotoxicity via inhibition of multiple toxin and extrusion proteins (MATEs). Toxicol Appl Pharmacol 273:100-109.

Lowry OH, Rosebrough NJ, Farr AL, and Randall RJ (1951) Protein measurement with the Folin phenol reagent. J Biol Chem 193:265-275.

Lu M, Radchenko M, Symersky J, Nie R, and Guo Y (2013) Structural insights into H+-coupled multidrug extrusion by a MATE transporter. Nat Struct Mol Biol 20:1310-1317.

Martínez-Guerrero LJ, Evans KK, Dantzler WH, and Wright SH (2016a) The multidrug transporter MATE1 sequesters OCs within an intracellular compartment that has no influence on OC secretion in renal proximal tubules. Am J Physiol Renal Physiol 310:F57-F67.

Martínez-Guerrero LJ, Morales M, Ekins S, and Wright SH (2016b) Lack of influence of substrate on ligand interaction with the human multidrug and toxin extruder, MATE1. Mol Pharmacol 90 254-264.

Ministry of Health, Labor and Welfare (2018) Guideline on drug interaction for drug developmen and appropriate provision of information.

Miyake T, Kimoto E, Luo L, Mathialagan S, Horlbogen LM, Ramanathan R, Wood LS, Johnson JG, Le VH, Vourvahis M, et al. (2020) Identification of appropriate endogenous biomarker fo risk assessment of multidrug and toxin extrusion protein-mediated drug-drug interactions in healthy volunteers. Clin Pharmacol Ther DOI: 10.1002/cpt.2022 [published ahead of print].

Miyauchi H, Moriyama S, Kusakizako T, Kumazaki K, Nakane T, Yamashita K, Hirata K, Dohmae N, Nishizawa T, Ito K, et al. (2017) Structural basis for xenobiotic extrusion by eukaryotic MATE transporter. Nat Commun 8:1633.

Motohashi H and Inui K (2013) Multidrug and toxin extrusion family SLC47: physiological, pharmacokinetic and toxicokinetic importance of MATE1 and MATE2-K. Mol Aspects Med 34 $661-668$
Nakada T, Kudo T, Kume T, Kusuhara H, and Ito K (2019) Estimation of changes in serum creatinine and creatinine clearance caused by renal transporter inhibition in healthy subjects. Drug Metab Pharmacokinet 34:233-238.

Prasad B, Johnson K, Billington S, Lee C, Chung GW, Brown CD, Kelly EJ, Himmelfarb J, and Unadkat JD (2016) Abundance of drug transporters in the human kidney cortex as quantified by quantitative targeted proteomics. Drug Metab Dispos 44:1920-1924.

Stocker SL, Morrissey KM, Yee SW, Castro RA, Xu L, Dahlin A, Ramirez AH, Roden DM, Wilke RA, McCarty CA, et al. (2013) The effect of novel promoter variants in MATE1 and MATE2 on the pharmacokinetics and pharmacodynamics of metformin. Clin Pharmacol Ther 93:186-194.

Tanaka Y, Hipolito CJ, Maturana AD, Ito K, Kuroda T, Higuchi T, Katoh T, Kato HE, Hattori M, Kumazaki K, et al. (2013) Structural basis for the drug extrusion mechanism by a MATE multidrug transporter. Nature 496:247-251.

Terada T and Inui K (2008) Physiological and pharmacokinetic roles of $\mathrm{H}+$ /organic cation antiporters (MATE/SLC47A). Biochem Pharmacol 75:1689-1696.

Thomas JA, Buchsbaum RN, Zimniak A, and Racker E (1979) Intracellular pH measurements in Ehrlich ascites tumor cells utilizing spectroscopic probes generated in situ. Biochemistry 18:2210-2218.

Tsuda M, Terada T, Ueba M, Sato T, Masuda S, Katsura T, and Inui K (2009) Involvement of human multidrug and toxin extrusion 1 in the drug interaction between cimetidine and metformin in renal epithelial cells. J Pharmacol Exp Ther 329:185-191.

U.S. Food and Drug Administration (2020) In vitro drug interaction studies-cytochrome P450 enzyme- and transporter-mediated drug interactions.

Yonezawa A and Inui K (2011a) Importance of the multidrug and toxin extrusion MATE/SLC47A family to pharmacokinetics, pharmacodynamics/toxicodynamics and pharmacogenomics. $B r$ J Pharmacol 164:1817-1825.

Yonezawa A and Inui K (2011b) Organic cation transporter OCT/SLC22A and H(+)/organic cation antiporter MATE/SLC47A are key molecules for nephrotoxicity of platinum agents. Biochem Pharmacol 81:563-568

Address correspondence to: Hiroyuki Kusuhara, Laboratory of Molecular Pharmaceutics, Graduate School of Pharmaceutical Sciences, The University of Tokyo, 7-3-1, Hongo, Bunkyo-ku, Tokyo 113-0033, Japan. E-mail: kusuhara@mol. f.u-tokyo.ac.jp 